\title{
INFORMAÇÃO PÚBLICA MUNICIPAL: Um caso de reengenharia
}

\author{
Justino Alves Lima \\ Maria Sônia S. Carvalho
}

\begin{abstract}
ResumoNeste trabalho apresentamos a realidade da Biblioteca Pública Municipal João Ribeiro, de Laranjeiras, em Sergipe, que, como tantas outras bibliotecas publicas no Brasil, funciona como uma biblioteca escolar. Apresentando projetos à Administração Pública Municipal, propomos mudanças para que, consonante com a atual realidade, a BPMJR seja mais funcional e aproxime-se da sua comunidade.
\end{abstract}

Palavras-Chave

Biblioteca Pública - Biblioteca Escolar

\section{INTRODUÇÃO}

Situada na zona central do Estado de Sergipe, na região do Vale do Cotinguiba, uma outrora próspera região açucareira, distante de Aracaju, a apenas $18 \mathrm{Km}$, a cidade de Laranjeiras convive com a majestade de seus casarões coloniais. Com $191 \mathrm{Km}$ de extensão territorial, o seu clima que oscila entre $24^{\circ} \mathrm{C}$ e $26^{\circ} \mathrm{C}$, e uma umidade relativa do ar de $78 \%$ em média, é um convite anual para visitar o que se considera um "museu a céu aberto".

Coerente com a longevidade dos seus majestosos casarões, a atividade financeira principal conseguiu dobrar o tempo e continua sendo a indústria açucareira e o fabrico do álcool.

Laranjeiras, patrimônio histórico estadual, orgulha-se da imponência de seus monumentos, divididos entre os casarões coloniais e as igrejas seculares, e da celebridade de filhos ilustres.

A cidade convive com duas frases que retratam o seu potencial histórico-cultural. A primeira, vinda do século passado, eternizou-a como a "Athenas Sergipana", numa alusão a famosa e gloriosa Athenas. A segunda, "Museu a Céu Aberto", da nossa época, faz justiça ao seu valioso conjunto arquitetônico de extraordinário valor histórico-cultural.

Os seus "heróis" nativos, eternizados através das diversas correntes literárias, tornam os tempos memoriais para esta Athenas Sergipana; enquanto os sobradões coloniais, que retratam o seu conjunto arquitetônico, fixam no tempo a sua marca de "museu a céu aberto".

De 1878 a 1904, Laranjeiras teve o seu "período de ouro". Período este que configurou o título de Athenas Sergipana. A efervescência cultural da cidade pôde ser medida nos dois grandes teatros o Santo Antônio e o São Pedro, por onde desfilaram grandes nomes nacionais. Nada menos que seis jornais pontificaram nessa época: O Horizonte, O Laranjeirense, O Republicano, O Cotinguiba, O Novo Século, e O Gripho. Colégios foram seis: Inglês, Americano, Sant'Anna, Coração de Jesus, Nossa Sra. da Conceição e a Escola Laranjeirense. Despontaram ainda no período de ouro, o Gabinete de Leitura e os Clubes Dramáticos.

Em novembro de 1973, através do Decreto 2.726/73, foi criado o Centro de Cultura, na casa onde nasceu João Ribeiro, em Laranjeiras. A 
casa de João Ribeiro já era monumento histórico tombado pelo Departamento de Cultura do Patrimônio Histórico de Sergipe, pelo Decreto 2.048 , de 1971. Considerava-se que a criação de um Centro de Cultura na casa de João Ribeiro contribuiria para o engrandecimento cultural da tradicional Laranjeiras.

O Centro passava a funcionar inicialmente com o acervo cultural de João Ribeiro, o que originou o Museu de João Ribeiro. Em agosto de 1974, a Biblioteca Pública Municipal, que estava desativada, passava a fazer parte do Centro de Cultura João Ribeiro, sendo denominada Biblioteca Pública Municipal João Ribeiro.

A instituição cultural biblioteca, incluída na paisagem histórica-cultural da cidade monumento Laranjeiras, desde 1941, funcionava no sobrado Antônio de Freitas Brandão com o nome de Biblioteca Moreira Guimarães. Entretanto, pouca informação existe sobre a mesma. Quanto ao seu acervo, não existem indícios de que destino tomou.

Retratada como repartição pública e premida pelo exercício da cessão da informação a escolares, a Biblioteca Pública Municipal João Ribeiro vive dissociada da comunidade. Para superar os impasses do cotidiano, verificou-se a necessidade de um estudo que introduzisse modificações na estrutura da Biblioteca. Um processo de reengenharia da informação que alterasse a perspectiva institucional na transferência de informação primeiro dimensionando um novo fazer bibliotecário no sentido de produzir informações sobre os monumentos da cidade e seus personagens ilustres e folclóricos e segundo aproximando a Biblioteca da comunidade.

\section{JOÃO RIBEIRO E A BIBLIOTECA}

João Ribeiro, nascido em 24 de julho de 1860, um dos filhos ilustres de Laranjeiras, foi o precursor do jornalismo científico no Brasil. Foi também quem ministrou o primeiro curso de folclore na Biblioteca Nacional do Rio de Janeiro.

Coube a Biblioteca Pública de Laranjeiras a honra de receber o seu nome (de João Ribeiro) e ficar localizada no Centro de Cultura João Ribeiro.
Criada através de convênio entre o Governo do Estado (uma vez que o Centro de Cultura João Ribeiro é estadual) e a Prefeitura Municipal, a João Ribeiro passou a funcionar em 9 de agosto do ano de 1974 com material, acervo e pessoal mantidos pelo poder municipal. Como acervo, entendiam-se os cem livros doados pelo Instituto Nacional do Livro (I.N.L.) ao Centro de Cultura João Ribeiro, como resultado de solicitação pessoal de Ema Ribeiro Acioly, filha de João Ribeiro.

Transcorridos 20 anos da sua criação, a João Ribeiro é hoje uma das 26 bibliotecas mantidas pelo poder público municipal de Sergipe. Um universo de apenas $24,53 \%$ das bibliotecas sergipanas. Este baixo índice de bibliotecas públicas municipais é apenas um dado. Neste pequeno universo, vamos encontrar uma situação de desconforto quando verificadas as estruturas das bibliotecas: desqualificação de pessoal; não alocação de recursos; falta de atualização dos acervos; e a própria desintegração entre as bibliotecas públicas sergipanas.

\section{A BPMJR E AATUAL TRANSFERÊNCIA DE INFORMAÇÂO}

Se existe um clima de vanguarda por ter sido criada a Biblioteca Pública Municipal João Ribeiro (BPMJR), no contexto de um centro cultural 20 anos atrás, o mesmo não ocorre com a sua prática.

Localizada em uma cidade onde a prática de bibliotecas escolares é inexistente, a BPMJR vê-se na eminência de suprir as necessidades das pesquisas escolares. Uma situação comum no país.

Com cinco escolas públicas na zona urbana e 19 na zona rural, o município conta com 6.434 alunos matriculados, distribuídos na zona urbana (3.347) e na zona rural (3.087), conforme tabela 1 a seguir: 
Tabela 1

REDE ESCOLAR X ALUNOS MATRICULADOS

\begin{tabular}{|c|c|c|c|}
\hline Localização & $\begin{array}{c}\text { Rede } \\
\text { Estadual }\end{array}$ & $\begin{array}{c}\text { Rede } \\
\text { Municipal }\end{array}$ & $\begin{array}{c}\text { Alunos } \\
\text { Matriculados }\end{array}$ \\
\hline Zona urbana & 03 & 02 & 3.347 \\
\hline Zona rural & 02 & 17 & 3.087 \\
\hline TOTAL & 05 & 19 & 6.434 \\
\hline
\end{tabular}

Fonte: Secretaria Municipal de Educação de Laranjeiras

O acervo da João Ribeiro não ratifica em termos quantitativos a prática da biblioteca escolar, uma vez que o acervo predominante é o de literatura, conforme tabela 2. Por outro lado a prática da biblioteca escolar pode ser conferida através do uso do acervo de acordo com a tabela 3.

Tabela 2

ACERVO DA BPMJR - EM VOLUMES

\begin{tabular}{|c|c|}
\hline Literatura & 4.080 \\
\hline Didáticos & 2.100 \\
\hline Periódicos & 1.125 \\
\hline Referência & 1.031 \\
\hline TOTAL & 8.336 \\
\hline
\end{tabular}

Fonte: Biblioteca Pública Municipal João Ribeiro

Tabela 3

UTILIZAÇÃO DA BPMJR - ÚLTIMOS 06 MESES

\begin{tabular}{|l|c|c|c|c|c|c|}
\hline Utilização /// Meses & abr & maio & jun & jul & ago & set. \\
\hline Empréstimos & 11 & 12 & 18 & 17 & 10 & 15 \\
\hline Consultas & 873 & 757 & 595 & 456 & 1.157 & 965 \\
\hline
\end{tabular}

Fonte: Biblioteca Pública Municipal João Ribeiro

Assim, considerando-se os meses analisados, dos 8.336 livros do acervo, houve uma utilização de aproximadamente 14 livros emprestados ao mês, enquanto que pesquisados in loco foram utilizados, em média, 800 livros ao mês. Considerando-se ainda que somente os livros da classe de literatura são emprestados e, portanto, todo o resto do acervo (didáticos, referência e periódicos) somente pode ser utilizado na própria biblioteca, caracteriza-se o uso da biblioteca eminentemente de cunho escolar. 
Observa-se ainda que a menor incidência de pesquisa verificou-se nos meses de junho e julho, tradicionalmente período de férias, inversamente aos livros de literatura, que tiveram maior incidência de empréstimo nos meses referidos. É fato também que no ano de 1993, pego como mostra, durante os meses citados acima, houve aulas nas escolas da rede estadual, motivadas pela extensão do calendário escolar, em virtude de greve, o que justifica o resíduo de pesquisa.

Os dados acima apresentados, trazem à Biblioteca Pública de Laranjeiras ao lugar comum das bibliotecas públicas brasileiras: a grande biblioteca escolar. Fica caracterizado que o seu público real é o da biblioteca escolar. Dado a falta de bibliotecas escolares, crianças entre 7 e 15 anos, que frequentam o curso de primeiro grau, procuram a Biblioteca Pública.

A Biblioteca por sua vez para melhor informar, procura adequar-se à demanda escolar e a cada dia adquire a feição de biblioteca escolar, fugindo do seu destino, do seu público potencial, que é o grande público: a comunidade na sua totalidade.

Nessa adequação, a Biblioteca acomodase e passa a fornecer apenas a informação que nela existe chegando a ser considerada a ideal, malgrado a desatualização do acervo.

Assim, a Biblioteca Pública Municipal João Ribeiro passa a ser considerada para a juventude laranjeirense a grande e única referência para as suas pesquisas e consultas escolares.

\section{A BPMJR E A TRANSFERÊNCIA DE INFORMAÇÃO}

Como vimos no item anterior, a BPMJR entrou no último decênio do século 20, transferindo uma informação estática e atendendo majoritariamente a uma parcela da comunidade: a estudantil. Não se posterga o mérito desse atendimento, nem o seu crédito. É necessário, entretanto, ampliar de forma radical e abrangente o público a ser atendido. É preciso que a Biblioteca evolua com a sociedade.

No Brasil do final do século 20, o segmento das bibliotecas públicas, salvo honrosas exceções, continua com as suas ações limitadas. As exceções ficam por conta dos Estados que já implantaram os seus Sistemas Estaduais de Bibliotecas Públicas e que contam com o apoio dos administradores da cultura. A implantação dos Sistemas por si só não torna as bibliotecas públicas mais atraentes.

No caso do isolamento de bibliotecas públicas municipais em Estados que não consignaram nas suas políticas culturais a implantação dos Sistemas, fica caracterizado que, neste caso, as bibliotecas atuam cada uma por si e o Estado contra todas.

Em Laranjeiras, não dá mais para conviver com o descaso e a indiferença estaduais. Por isso, a Biblioteca Pública Municipal pautou por uma intervenção na sua realidade que, mesmo sem se descuidar do seu fazer atual, a cessão da informação escolar, amplie serviços e atraia o seu público potencial. Decidiu-se então pela apresentação de projetos à Administração Pública Municipal numa perspectiva de uma biblioteca pública consonante com as postulações sócioculturais da comunidade.

\subsection{Projetos}

3.1.1 Projeto Autonomia;

3.1.2 Projeto Automação;

3.1.3 Projeto Ampliação;

3.1.4 Projeto Memória;

3.1.5 Projeto Fazer Cultural.

\subsubsection{Projeto Autonomia}

Embora, nestes 20 anos de existência, a BPMJR tenha adquirido material bibliográfico para compor o seu acervo, via compra, esta prática tem sido exclusivamente para livros didáticos e de referência e tem-se constituído em atitudes isoladas e espaçadas das administrações municipais. $\mathrm{O}$ seu acervo tem sido construído principalmente à base de doações. Primeiro, os cem livros doados pelo INL; posteriormente, doações de particulares e entidades governamentais várias. No entanto, um acervo que se perfila em doações normalmente não representa as aspirações da comunidade.

No Nordeste, temos ainda muito ressoante a voz de Luís Gonzaga a cantar a miséria nos versos "se o doutor dá uma esmola /a um homem que é são /ou the mata de vergonha / ou vicia o 
cidadão." O mesmo acontece com a biblioteca. As campanhas de doação, geralmente protagonizadas por leigos à frente das bibliotecas públicas, só criam o vício da construção de um acervo não planejado, não qualificado, não representativo das necessidades informacionais da comunidade e eximem a classe políticoadministrativa de cumprir o seu papel políticosocial, de estabelecer suas responsabilidades, alocando recursos na biblioteca pública.

O Manifesto da Unesco para a biblioteca pública recomenda que sua manutenção deva ser assegurada totalmente pelos cofres públicos. Isto porque "os custos do serviço de biblioteca devem ser cobertos com recursos públicos proporcionados pelo governo central ou pela administração local ou por ambos." Para tal "têm que ser previstas as fontes que assegurarão o financiamento de forma contínua, e todas as autoridades locais que detenham algum grau de responsabilidade pela supervisão deverão ter a faculdade concedida por lei de levantar recursos financeiros."

Evidentemente, o Manifesto não tem o rigor do cumprimento, mas sim da orientação. É então baseado no princípio da orientação que a BPMJR tentará junto à Administração Pública Municipal a conscientização para a alocação de recursos financeiros necessários e suficientes para o funcionamento da Biblioteca. O Projeto Autonomia prevê tal alocação de recursos em percentual a ser estipulado do recurso destinado à Secretaria Municipal de Educação, Cultura, Esporte, Lazer e Turismo.

Os recursos financeiros destinados à Biblioteca terão o fim específico de estabelecer um acervo ampliado, seja em quantidade, seja em novos suportes de informação. O objetivo é aproximar-se da disponibilidade de coleções, conforme recomendações das Normas para Bibliotecas Públicas emanadas através do Manifesto da Unesco.

\subsubsection{Projeto Automação}

Próximas do século 21, as bibliotecas públicas sergipanas, sem exceção, ainda habitam as trevas da tecnologia. Não existe nenhuma que esteja automatizada. A probabilidade da existência de um sistema de bibliotecas públicas informatizadas é quase inexistente nos dias atuais.
Embora existam alguns softwares de automação de bibliotecas em uso no Brasil e com amplo sucesso, estes são exclusivos para bibliotecas que estejam em ambientes operacionais "mainframes". Fica claro, se considerarmos o que está posto no parágrafo anterior, que estamos longe de atingirmos este estágio.

Assim, a solução seria um software para PC estabelecendo uma automação local. O Projeto Automação propõe a aquisição de equipamento, um micro e seus periféricos, e a aquisição do programa aplicativo necessário. $\mathrm{O}$ programa aplicativo aqui suscitado pode ser um dos sistemas de automação de bibliotecas, em uso hoje no país, desde que desenvolvido para operar em PC.

Com este projeto, a BPMJR não tem a pretensão de estabelecer uma automação que lhe permita recuperar informações de outras bibliotecas, nem a possibilidade de absorção de acervo com grande volume de títulos. Mas tão somente a necessidade de automatizar o seu acervo, recuperando informação e atendendo ao usuário com mais eficiência.

\subsubsection{Projeto Ampliação}

Funcionando desde 1974 no Centro de Cultura João Ribeiro, a Biblioteca Pública ocupa mais da metade do espaço físico do Centro. Dos $175 \mathrm{~m} 2$ de área construída do Centro, a Biblioteca ocupa $104 \mathrm{~m} 2$, restando $48 \mathrm{~m} 2$ para o museu e $23 \mathrm{~m} 2$ para recepção e área de serviços (copa/ cozinha e banheiros).

Começando a funcionar com um acervo de apenas cem livros, passando para os atuais 8.000, o que significa acréscimo de estantes, mobília para acomodar os novos funcionários e mobília para os usuários, a BPMJR estrangulou o espaço que lhe era destinado, e já não comporta mais crescimento, seja a nível de acervo, seja a nível de mobília/equipamento.

Adicione-se a esta impossibilidade de crescimento o inconveniente da acomodação de usuários espremidos em $24 \mathrm{~m} 2$, uma vez que as outras salas são ocupadas com o acervo, processo técnico e administração.

O que dizer então da necessidade de espaço para as atividades culturais que precisam ser 
desenvolvidas pela Biblioteca? É com este sentimento, integrado à perspectiva do estabelecimento de uma proposta de atividade cultural permanente, que a João Ribeiro propõe a ampliação do Centro de Cultura João Ribeiro.

Com $91 \mathrm{~m} 2$ de área ainda disponível, o Projeto Ampliação propõe a construção de um anexo moderno que acomode usuários/ouvintes em palestras, seminários, reuniões e que seja ocupado pelos usuários de rotina, para os trabalhos em grupo, liberando a sala de leitura hoje existente para leituras individuais. Este anexo seria uma construção de dois pavimentos, sendo o pavimento térreo destinado exclusivamente para exposições.

Tem a Biblioteca Pública Municipal João Ribeiro a noção exata das dificuldades da aceitação deste projeto, tendo em vista que a Casa de João Ribeiro é tombada pelo Patrimônio Histórico Estadual. Tem também a João Ribeiro a consciência de que o tombamento deve ser respeitado e não se propõe em nenhum momento mexer na estrutura da Casa, respeitando-se até as dependências de uso exclusivo dos servidores (copa/cozinha/banheiros). Ademais, o anexo teria entrada individualizada, funcionando como prédio independente, por detrás da Casa de João Ribeiro.

Na impossibilidade da ampliação física no Centro de Cultura João Ribeiro, a proposta é para que a Biblioteca seja transferida para um imóvel próprio com espaço suficiente para a acomodação dos serviços atuais e futuros.

O Projeto Ampliação é uma justa reivindicação, considerando que nestes 20 anos o acervo da Biblioteca cresceu de cem para 8.000 volumes, cresceram juntos o seu público e a sua importância. Com a ampliação, pretende-se não só ampliar o espaço que se destina ao usuário, como também novos serviços à comunidade.

\subsubsection{Projeto Memória}

A Biblioteca Pública Municipal João Ribeiro tem assumido a postura de mera reprodutora da oficialidade livreira no seu âmbito de acessora da informação. Tal postura não é privativa da João Ribeiro, mas a ela cabe redimensionar o seu âmbito de atuação. Assim, no processo de reengenharia da informação, cabe à mesma assumir um novo fazer na gestão da transferência da informação.

Em Laranjeiras, é necessário resgatar o interesse pelo passado como forma de preservar o presente. Isto porque nela o passado se faz presente. $\mathrm{O}$ resgate da história dos monumentos e casarios coloniais da cidade é uma reconstituição da história da cidade. Com este novo perfil, o de procurar fomentar informações, a Biblioteca pretende envolver a comunidade laranjeirense com a escrita da sua história.

A idéia de fazer com que a Biblioteca trabalhe o resgate da história dos monumentos laranjeirenses reside no fato da inexistência de dados exaustivos sobre os mesmos. Os raros livros que retratam Laranjeiras apontam dados residuais. As informações herdadas chegam a ser simplórias perante a grandeza do passado da cidade.

Justifica-se este projeto baseado na premissa de que, modernamente, as bibliotecas lutam para se libertarem e se livrarem da imagem de locais sacrossantos de livros. No processo da construção da imagem de uma instituição dinâmica, as bibliotecas procuram alcançar a informação que não está impressa nos livros convencionais.

Com este projeto, a BPMJR tenta romper a dominação da informação convencional e inserir no seu acervo informações ainda não conhecidas, que são primordiais para entender a cidade de Laranjeiras dentro do seu contexto históricocultural.

O objetivo deste projeto é coletar informações sobre o patrimônio histórico-cultural de Laranjeiras, com o fim específico de incorporálas ao acervo da Biblioteca Pública. A partir das informações coletadas objetiva-se: primeiro oportunizar ao usuário do cotidiano uma leitura mais apropriada sobre a história da sua cidade; segundo atender a grande demanda de informações didático-turísticas de que tem sido protagonista a Biblioteca João Ribeiro.

\subsubsection{Projeto Fazer Cultural}

Não é mais possível que uma Biblioteca Pública atue somente cedendo informações a estudantes de primeiro e segundo graus. É necessário uma atuação de caráter cultural que 
associe a biblioteca pública à comunidade como um todo.

Assim é que baseado em novas teorias e práticas já em execução em alguns Estados do país, pretende-se estabelecer um fazer cultural, que não pontifique somente os eventos, mas uma política cultural definida.

No Projeto Fazer Cultural será dado ênfase ao fazer cultural do próprio município. Rica em manifestações folclóricas, a cidade de Laranjeiras necessita tornar mais conhecida toda esta riqueza. A BPMJR pretende ser o centro irradiador desta cultura para o próprio Estado de Sergipe. Neste Projeto, como no Projeto Memória, a Biblioteca pretende ser o produtor da informação, saindo do seu lugar estático de mero repassador de informações.

O Projeto Fazer Cultural será implantado, obedecendo um calendário de atividades culturais a ser estabelecido ano a ano. Para levar a efeito a programação agendada, a Biblioteca buscará parceiros financeiros na iniciativa privada, ancorada na Lei Estadual de Incentivo Financeiro à Cultura.

\section{CONCLUSÃO}

Em Sergipe, as bibliotecas têm sido isoladas e esquecidas pelos governos estaduais, sucessivamente. Na realidade, os governos constituídos têm sido contra elas, dentro dos seus imobilismos culturais. Não se cogita, dentro das gestões governamentais, de que esta é uma instituição indispensável no amplo conjunto das instituições e manifestações culturais.

Como prevê o Manifesto da Unesco sobre a Biblioteca Pública, esta deve "adotar uma perspectiva atuante e positiva, demonstrando o valor de seus serviços e estimulando seu uso". É desta forma que em Laranjeiras informação e cultura via Biblioteca Pública tendem a ser concretas.

É com esta reengenharia, que aponta saídas para mudança de comportamento a nível orgânico-funcional, que se busca o apoio da administração pública municipal. Para tal, a apresentação de projetos definidos como essenciais e apontados neste trabalho, é a perspectiva, uma vez incorporados pela administração municipal, da existência de uma Biblioteca Pública transferindo informações numa ótica mais pública e mais cultural.

Citada como repartição pública em atividade na cidade de Laranjeiras, a Biblioteca Pública Municipal João Ribeiro quer se desprender deste rótulo. Neste sentido, o trabalho ora apresentado, resultado de um trabalho de reengenharia da informação, tem o mérito de tentar estabelecer, através da consignação dos projetos, uma relação futura de cumplicidade entre a Biblioteca e a cidade, melhorando os seus serviços e buscando um padrão de qualidade no atendimento ao público.

Em nome da reengenharia, a BPMJR pretende concretizar-se como parte integrante do museu a céu aberto, que é a cidade de Laranjeiras. Eliminando vícios de uma informação estanque, pretende ser uma casa de informação e cultura que possa interferir nos destinos da cidade enquanto fórum turístico.

\section{REFERÊNCIAS BIBLIOGRÁFICAS}

BRASIL. Ministério do Interior. Banco do Nordeste do Brasil S.A. Laranjeiras "um museu a céu aberto”. Fortaleza : 1983.

FEDERAÇÃO INTERNACIONAL DE ASSOCIAÇÕES DE BIBLIOTECÁRIOS. Seção de Bibliotecas Públicas. Normas para bibliotecas públicas. Trad. Antônio Agenor Briquet de Lemos. São Paulo : Quíron, 1976.

OLIVEIRA, Philadelpho. Registro de fatos históricos de Laranjeiras. 2.ed. Aracaju : Secretaria de Educação e Cultura do Estado de Sergipe, 1981.

SERGIPE. Secretaria de Estado da Educação e Cultura. Conselho Estadual de Cultura. Levantamento de informações culturais: situação das bibliotecas em Sergipe: relatório. Aracaju, 1985. 


\section{Justino Alves Lima}

Bibliotecário da Universidade Federal de Sergipe

\section{Maria Sônia S. Carvalho}

Diretora do Centro de Cultura João Ribeiro

\section{Title}

Public information: a reengineering case

AbstractsIn this work we show the reality of the João Ribeiro Municipal Public Library, in Laranjeiras, Sergipe, which, like so many other public libraries in Brasil, functions as a school library. By presenting projects to the Municipal Public Administration, we propose changes to make the JRMPL more functional and closer to its community by the year 2.000.

\section{Keywords}

Public Library - School Library 